\title{
Current knowledge for the western blot normalization.
}

\author{
Sang Y. Lee* \\ Department of Neurosurgery, The Pennsylvania State University College of Medicine, Hershey, PA 17033, USA
}

\begin{abstract}
Western blot (WB) is a fundamental technique in cell and molecular biology, and cancer biology research, used to separate and identify cellular proteins. The techniques and procedures for WB have progressed over the last 30 years. However, there is still debate whether to perform protein normalization using housekeeping proteins or total protein normalization. Here, the key factors for WB normalization methods are summarized and potential areas for future research are presented.
\end{abstract}

Keywords: Housekeeping protein, Normalization, Western blot.

Accepted on 09 March 2018

\section{Introduction}

Western blot (a.k.a Western blotting, Immunoblotting, WB), a key molecular biology technique, is used to detect the presence, or the expression level, of a specific protein in a complex mixture extracted from cells or tissues. Since WB technique was first published in 1979-1981 [1-4], there have been tremendous developments in WB procedures, as well as in WB equipment. For example, new techniques have been reported, or are in recent development, such as single cell western blotting, single cell-resolution western blotting, and fully automated simple western blotting [5-8]. The improvements in WB procedure span among all WB steps: cell lysis buffer, sodium dodecyl sulfate polyacrylamide gel electrophoresis (SDS-PAGE) gels, transfer apparatus, detection methods/ reagents/systems etc. $[9,10]$. For successful and reproducible WB data, however, a researcher should also consider other key factors, such as antibody validation, normalization, replicate, proper control, and statistical analysis [11-13].

Recently, among several key factors, the importance of normalization, along with data reproducibility, was highlighted by scientists using WB technique [14]. Normalization is a process for internal loading control to mathematically correct for small, unavoidable sample-to-sample and lane-to-lane variations. Internal loading controls are endogenous protein(s), unaffected by experimental conditions, and used as an indicator of sample concentration. Normalization, along with a rigorous methodology, is critical in order to obtain reproducible data from quantitative and semi-quantitative WB [15]. The accuracy of protein expression data in WB relies on how the signal band is normalized and whether an appropriate normalization method has been used. To normalize protein intensity, several methods can be used: e.g. housekeeping proteins (HKPs), total protein staining, and signaling proteins. In the past, most WB data have used HKPs as a major normalization method. The most often used HKPs for WB quantification are actins (e.g., $\beta$ actin), tubulins (e.g., $\alpha$-tubulin), and glyceraldehyde 3phosphate dehydrogenase (GAPDH) (Table 1). In general, these proteins are highly expressed in cells and tissues. Therefore, these HKPs are easily used and detected in a saturated condition, by unaware researchers. Moreover, the expression of GAPDH is iron responsive [16]. When a phosphorylated signal is compared to an un-phosphorylated target protein, signaling protein(s) are used as a normalization method; however, recently, normalization of signal intensity to total protein loading is preferred to HKPs [17]. This concept is supported by several journals and societies [14]. One reason is that normalization by HKPs can perform only one protein, as a reference. In addition, HKPs are frequently affected by pathological conditions or experimental conditions, although another report found that HKPs are not altered [18-21]. Li and Shen [19] summarized the alteration of HKPs based on biological or pathological conditions. One example of a pathological condition is that $\beta$-actin and $\beta$-tubulin expression is altered, while GAPDH is a reliable internal control in ischemic myocardinal infarction animal models [21]. $\beta$-actin expression is also increased in spinal cord injuries [22]. The following experimental conditions can affect HKPs protein expression: cell confluence level upon cell collection, loading protein amount, cell/tissue type, etc. For example, protein expression of $\alpha$-tubulin and GAPDH increased significantly in mouse NIH3T3 fibroblasts, by cell confluence increase from $10 \%$ to $100 \%$; however, heat shock protein 90 (Hsp90) and $\beta$ actin protein expression are not affected by cell confluence [23]. Two groups [18-20] found that the $\beta$-actin antibody cannot detect actin levels in a higher total protein loaded condition. Although we found a linear range of $\alpha$-tubulin and $\beta$ actin protein expression up to $30 \mu \mathrm{g}$ of total protein in human neuroblastoma SK-N-AS cells, Dittmer and Dittmer [18] observed that there is no linear range of $\beta$-actin between $1.9 \mu \mathrm{g}$ and $7.5 \mu \mathrm{g}$ of human MDA-MB-231 breast cancer cells protein extract. When comparing obese and non-obese samples of human adipose tissue, $\beta$-actin showed consistent expression, whereas GAPDH and $\beta$-tubulin showed altered expression [24]. In addition, $\beta$-actin expression is increased in kidney tumor tissue compared to normal tissue [25]. The alteration in HKPs can result in inaccurate data analysis and interpretation. Therefore, if a researcher wants to use HKPs as a normalization method, he/she should demonstrate that their HKPs are not altered by experimental conditions, at the validation stage. In 
addition, HKPs band should not be saturated and should use a linear range for best quantitative WB.

Table 1. List of HKPs used for internal control for Western blotting normalization (modified from information at www.abcam.com/ primary-antibodies/loading-control-guide and www.bio-radantibodies.com).

\begin{tabular}{|c|c|c|c|}
\hline \multirow{2}{*}{$\begin{array}{l}\text { Sample type } \\
\text { or location of } \\
\text { target } \\
\text { proteins }\end{array}$} & \multicolumn{3}{|l|}{ Internal controls } \\
\hline & $\begin{array}{l}\text { EGFR } \\
\text { (epidermal } \\
\text { growth factor } \\
\text { receptor) }\end{array}$ & $\begin{array}{l}\text { gp130 } \\
\text { (glycoprotein } \\
130)\end{array}$ & Pan-cadherin \\
\hline \multirow{3}{*}{$\begin{array}{l}\text { Whole cell/ } \\
\text { cytoplasm }\end{array}$} & $\mathrm{Na} / \mathrm{K}$-ATPase & $\begin{array}{l}\text { Transferrin } \\
\text { receptor }\end{array}$ & $\begin{array}{l}\text { HSP90 (heat shock } \\
\text { protein 90) }\end{array}$ \\
\hline & Calnexin & Tubulins & Actins \\
\hline & $\begin{array}{l}\text { GAPDH } \\
\text { (glyceraldehyde } \\
\text { 3-phosphate } \\
\text { dehydrogenase) }\end{array}$ & Cyclophilin A/B & Cofilin \\
\hline \multirow{3}{*}{ Nucleus } & Lamin B1 & $\begin{array}{l}\text { HDAC1 (histone } \\
\text { deacetylase 1) }\end{array}$ & YY1 (Yin and yang 1) \\
\hline & $\begin{array}{l}\text { TATA binding } \\
\text { protein TBP }\end{array}$ & $\begin{array}{l}\text { PCNA } \\
\text { (proliferating } \\
\text { cell nuclear } \\
\text { antigen) }\end{array}$ & $\begin{array}{l}\text { HPRT1 (hypoxanthine } \\
\text { guanine } \\
\text { phosphoribosyltransferas } \\
\text { e) }\end{array}$ \\
\hline & Histone $\mathrm{H} 1 / \mathrm{H} 3$ & $\begin{array}{l}\text { RPLP1 (60S } \\
\text { acidic ribosomal } \\
\text { protein P1) }\end{array}$ & \\
\hline Mitochondria & $\begin{array}{l}\text { HSP60 } \\
\text { shock protein } \\
60)\end{array}$ & $\begin{array}{l}\text { VDAC1/Porin } \\
\text { (voltage- } \\
\text { dependent } \\
\text { anion-selective } \\
\text { channel 1) }\end{array}$ & $\begin{array}{l}\text { COX IV (cytochrome c } \\
\text { oxidase IV) }\end{array}$ \\
\hline Serum & Transferrin & & \\
\hline
\end{tabular}

Meanwhile, total protein normalization can be performed using total protein staining, stain-free technology (pre-cast), or QuickStain technology [26-30]. Each method has distinct features regarding sensitivity, reproducibility, process, and dynamic range. Although there is a report of uneven staining across the blot [31], the comparison of these methods indicates that stain-free technology and QuickStain technology show better sensitivity and reproducibility compared to other staining methods [32]. Many commercial companies have developed new stain reagents and alternative systems for total protein normalization. The principle of stain-free, pre-cast gel is that halo-substituted organic compounds in the gel react with tryptophan residues upon irradiation with UV light, to form fluorescent compounds [28,29]. This pre-cast gel system produces high sensitivity ( $\sim 1 \mathrm{ng})$ and high reproducibility. In addition, QuickStain is based on Cyanine 5 (Cy5) NHS ester (N-hydroxysuccinimide ester) labeling of reactive amino groups in proteins before SDS-PAGE [29]. The pre-labeling of samples induces high sensitivity at sub-nanogram and high reproducibility with single incubation step. However, to use QuickStain technology, several special reagents and instruments, such as fluorescent imager, fluorescent marker and Cyanine ( $\mathrm{Cy} 3$ or $\mathrm{Cy} 2$ ) conjugate secondary antibody, are pre-required. Moreover, the success of both pre-cast and QuickStain technologies rely on the key steps of WB, like the success in traditional WB: well performed transfer of proteins from gel to the membrane, specificity of primary antibody, appropriate good software for total protein normalization. In addition, pre-cast and QuickStain technology depend on protein composition and/or require fluorescent imager to apply the methods. Although pre-cast and QuickStain technology based total protein normalization demonstrated good accuracy and reproducibility, it is not widely used, due to lack of equipment or knowledge in the field, et al. If a laboratory doesn't have a fluorescent imager, the laboratory needs to use HKPs as a normalization method for reproducible quantitative WB data analysis. In this situation, the researcher must run both HKPs and target proteins in linear range (e.g., $30 \mu \mathrm{g}$ total protein), as well as demonstrate that HKPs are not affected by experimental conditions. In our experience, it is difficult to demonstrate that HKPs are consistently expressed through experimental conditions. The researcher should consider testing the consistency of expression of abundantly expressed HKPs as well as less-abundantly expressed HKPs, to compare to the target protein's intensity. There is a well-organized table for loading controls [33]. Table 1 summarizes the most commonly used HKPs for internal controls for WB normalization.

Meanwhile, we must replicate our biological samples (biological replicates) and the number of replicate samples (technical replicates), for accuracy of data and reproducible data. These replicates are important because, without replication, it is difficult to determine whether an altered protein signal is real or artifact of experimental variation. Biological and technical replicates are not a concern when we compare two samples (e.g., wildtype $v s$. mutant) with only one variation factor, because three runs of SDS-PAGE are sufficient to analyze a target protein. If there are several factors, such as time course or a dose-dependent study, we need to run multiple SDS-PAGE to satisfy both biological replicates and technical replicates. In that case, it is recommended that we use the same membrane for multiple target proteins detection, without stripping membrane, because membrane stripping can decrease binding of proteins on the membrane or even cause a loss of proteins from the membrane. When we analyze the multiple-factor based variation effect, QuickStain technology is a good approach to pursue, because we can detect 4 target proteins' signal in a single WB (e.g., anti-mouse and anti-rabbit per each $\mathrm{Cy} 2$ or $\mathrm{Cy} 3$ ). Another, stronger alternative method is combination of both pre-cast and QuickStain technology. Following SDS-PAGE, using pre-cast gels, the gels are activated by UV and then transferred to the membrane. Next, the membrane is used for total protein normalization. In a later step, we can use fluorescent secondary antibody (Cy2, Cy3, Cy5 as well) rather than traditional HRPconjugated secondary antibody. Through this alternative method, we can detect 6 target proteins' signal in a single WB (e.g., anti-mouse and anti-rabbit, per each $\mathrm{Cy} 2$ or $\mathrm{Cy} 3$ or $\mathrm{Cy} 5$ ).

In summary, top leading journals should establish a guideline for WB normalization for the quality, accuracy, reproducibility, 
and transparency of publishing data. Authors should consider which method is best for WB normalization for their experiments. One report suggests that commonly used HKPs are more appropriate for highly expressed target proteins; and, total protein normalization is good for low-abundance target protein analysis [34]. If authors use a single protein as a normalization method, such as an HKP, they should test and include whole WB image pictures (not cut bands) for i) linear range determination of HKPs and target proteins, ii) expression of normalization control to experimental conditions to show the expression of HKPs is not affected by experimental conditions, iii) specificity of key primary antibodies as supplement information. Alternatively, the authors should use at least two HKPs (one abundantly expressed, the other less abundantly expressed) as an internal control. If researchers utilize a digital imaging system, combination of pre-cast and QuickStain technology is recommended for easy replicate experiments. In addition, the researchers should pay close attention that he/she uses their analyzing software in the correct manner. While debate over which normalization method is superior, a good approach is to demonstrate protein(s) normalization and total protein normalization.

\section{Acknowledgment}

This is supported from the Children's Miracle Network and Four Diamonds Funds. The author thanks Mrs. Sara Langan for critical editing.

\section{Conflicts of Interest}

No potential conflict of interest was disclosed.

\section{References}

1. Renart J, Reiser J, Stark GR. Transfer of proteins from gels to diazobenzyloxymethyl-paper and detection with antisera: A method for studying antibody specificity and antigen structure. Proc Natl Acad Sci. 1979;76:3116-20.

2. Towbin H, Staehelin T, Gordon J. Electrophoretic transfer of proteins from polyacrylamide gels to nitrocellulose sheets: Procedure and some applications. Proc Natl Acad Sci. 1979;76:4350-4.

3. Burnette WN. Western blotting: Electrophoretic transfer of proteins from sodium dodecyl sulfate-polyacrylamide gels to unmodified nitrocellulose and radiographic detection with antibody and radioiodinated protein A. Anal Biochem. 1981;112:195-203.

4. Mukhopadhyay R. The men behind Western blotting. ASBMB Today. March 2012:34-5.

5. Hughes AJ, Spelke DP, Xu Z, et al. Single-cell western blotting. Nat Methods. 2014; 11:749-55.

6. Kang CC, Yamauchi KA, Vlassakis JA, et al. Single cellresolution western blotting. Nat Protoc. 2016;11:1508-30.

7. Nguyen U, Squaglia N, Boge A, et al. ProteinSimple The Simple WesternTM: A gel-free, blot-free, hands-free Western blotting reinvention. Nature Methods. 2011. November. Advertising Feature v-vi. ProteinSimple web site (http://www.proteinsimple.com)
8. Mishra M, Tiwari S, Aldrin V. Protein purification and analysis: Next generation Western blotting techniques. Expert Rev Proteomics. 2017;14:1037-53.

9. Jensen EC. The basics of western blotting. Anat Rec (Hoboken). 2012;295:369-71.

10. Ghosh R, Gilda JE, Gomes AV. The necessity of and strategies for improving confidence in the accuracy of western blots. Expert Rev Proteomics. 2014;11:549-60.

11. Voskuil JL. The challenges with the validation of research antibodies. F1000Res. 2017; 6:161.

12. Taylor SC, Berkelman T, Yadav G, et al. A defined methodology for reliable quantification of Western blot data. Mol Biotechnol. 2013;55:217-26.

13. Gilda JE, Ghosh R, Cheah JX, et al. Western Blotting Inaccuracies with Unverified Antibodies: Need for a Western Blotting Minimal Reporting Standard (WBMRS). PLoS One. 2015;10:e0135392.

14. Fosang AJ, Colbran RJ. Transparency is the key to quality. J Biol Chem. 2015;290:29692-4.

15. Taylor SC, Posch A. The design of a quantitative western blot experiment. Biomed Res Int. 2014:361590.

16. Raje CI, Kumar S, Harle A, et al. The macrophage cell surface glyceraldehyde-3-phosphate dehydrogenase is a novel transferrin receptor. J Biol Chem. 2007;282:3252-61.

17. Collins MA, An J, Peller D, Bowser R. Total protein is an effective loading control for cerebrospinal fluid western blots. J Neurosci Methods. 2015;251:72-82.

18. Dittmer A, Dittmer J. Beta-actin is not a reliable loading control in western blot analysis. Electrophoresis. 2006;27:2844-5.

19. Li R, Shen Y. An old method facing a new challenge: revisiting housekeeping proteins as internal reference control for neuroscience research. Life Sci. 2013;92:747-51.

20. Bauer DE, Haroutunian V, McCullumsmith RE, et al. Expression of four housekeeping proteins in elderly patients with schizophrenia. J Neural Transm. 2009;116:487-91.

21. Nie $\mathrm{X}, \mathrm{Li} \mathrm{C}, \mathrm{Hu} \mathrm{S}$, et al. An appropriate loading control for western blot analysis in animal models of myocardial ischemic infarction. Biochem Biophys Rep. 2017; 12:108-13.

22. Liu NK, Xu XM. Beta-tubulin is a more suitable internal control than beta-actin in western blot analysis of spinal cord tissues after traumatic injury. J Neurotrauma. 2006; 23:1794-1801.

23. Greer S, Honeywell R, Geletu M, et al. Housekeeping genes; expression levels may change with density of cultured cells. J Immunol Methods. 2010;355:76-9.

24. Pérez-Pérez R, López JA, García-Santos E, et al. Uncovering suitable reference proteins for expression studies in human adipose tissue with relevance to obesity. PLoS One. 2012; 7:e30326.

25. Ferguson RE, Carroll HP, Harris A, et al. Housekeeping proteins: a preliminary study illustrating some limitations 
as useful references in protein expression studies. Proteomics. 2005;5:566-71.

26. Aldridge GM, Podrebarac DM, Greenough WT, et al. The use of total protein stains as loading controls: An alternative to high-abundance single-protein controls in semi-quantitative immunoblotting. J Neurosci Methods. 2008;172:250-4.

27. Eaton SL, Roche SL, Llavero Hurtado M, et al. Total protein analysis as a reliable loading control for quantitative fluorescent Western blotting. PLoS One. 2013;8:e72457.

28. Gilda JE, Gomes AV. Stain-free total protein staining is a superior loading control to $\beta$-actin for western blots. Anal Biochem. 2013;440:186-8.

29. Colella AD, Chegenil N, Tea MN, et al. Comparison of stain-free gels with traditional immunoblot loading control methodology. Anal Biochem. 2012;430:108-10.

30. Hagner-McWhirter $\AA$, Laurin Y, Larsson A, et al. Cy5 total protein normalization in Western blot analysis. Anal Biochem. 2015;486:54-61.
31. Taylor SC, Berkelman T, Yadav G, et al. A defined methodology for reliable quantification of Western blot data. Mol Biotechnol. 2013;55:217-26.

32. Total Protein Normalization: Which stain is the best for you? http://www.gelifesciences.com/

33. Loading control guide. http://www.abcam.com/primaryantibodies/loading-control-guide, http://www.bio-radantibodies.com

34. Western Blot Normalization. http:// www.azurebiosystems.com

\section{*Correspondence to:}

Sang Y. Lee

Department of Neurosurgery

The Pennsylvania State University College of Medicine

Hershey, PA 17033, USA

E-mail: SYL3@psu.edu 